\title{
Why do patients choose to consume Ayurvedic Medicines in Nepal? An exploratory study
}

\author{
Research Article
}

\section{Gandhiv Kafle ${ }^{*}$, Indira Bhattarai (Sharma) ${ }^{2}$, Arjun Kumar Shrestha ${ }^{2}$, Mohan Siwakoti ${ }^{3}$}

\author{
1. Ph. D. Scholar, Faculty of Agriculture, Agriculture and Forestry University, Chitwan, Nepal \\ 2. Professor, Agriculture and Forestry University, Chitwan, Nepal \\ 3. Professor, Central Department of Botany, Tribhuvan University, Kathmandu, Nepal
}

\begin{abstract}
Ayurvedic medicines are believed to bring harmony and balance in mind, body, spiritual well-being and social welfare of human. The reasons for preference for these medicines are of great interest for exploration. This study was carried out in Nepal in 2017 to explore the reasons for choosing to consume Ayurvedic medicines, with support of a separate survey focusing on these medicines containing Neopicrorhiza scrophulariiflora. An online survey $(\mathrm{n}=58)$ and face to face interviews $(\mathrm{n}=406)$ were administered using structured questionnaires to explore those reasons for choice. Neopicrorhiza scrophulariiflora (Pennell) D. Y. Hong (Scrophulariaceae) is a perennial alpine herb found in the subalpine as well as alpine zone of the eastern Himalayas comprising Sikkim, Nepal, Bhutan and China. Its rhizomes are medicinally important and in trade. Fewer or no side effects, preference to natural way of healing, belief regarding healing of disease, ease of access (availability and cost), and advertisement and recommendation from others were the major reasons that the patients chose to consume Ayurvedic medicines for own's healing. In case of Ayurvedic medicines containing Neopicrorhiza scrophulariiflora, majority of the patients believed that these medicines have fewer or no side effects, can cure illness particularly for long run of chronic diseases, were cheaper than allopathic medicines, were easily available to purchase and were recommended by family members. Healing was not successful in past from allopathic and other types of medicines of majority of the patients who preferred to consume Ayurvedic medicines containing Neopicrorhiza scrophulariiflora. Further scientific studies and interventions are recommended for concerned health authorities and nursing practitioners of Nepal to test and validate the safety and effectiveness of the consumption of Ayurvedic medicines
\end{abstract}

Keywords: Ayurvedic medicines, Patients, Neopicrorhiza scrophularififlora, Reasons for consumption, Nepal.

\section{Introduction}

Plants have been utilized for medicines and herbal products for thousands of years, initially as traditional preparations then as pure active principles with this knowledge and accumulated practice passing from generation to generation $(1,2)$. Medicinal plants are globally valuable sources of new medicines $(3,4)$. Medicines prepared from medicinal plants i.e. herbal medicines, can be placed under two broad categories: Firstly, they are included in complex mixtures containing a wide variety of compounds (e.g. infusions, essential oils, tinctures, or extracts), and secondly, they are used as pure, chemically defined active principles (5). Herbal medicine has long been used for the prevention and treatment of a wide range of medical conditions, as well as for general health enhancement $(6,7)$. For primary healthcare, $80 \%$ of people in developing countries are dependent on herbal medicines and about $25 \%$ of prescribed medicines in

*Corresponding Author:

\section{Gandhiv Kafle}

Faculty of Agriculture,

Agriculture and Forestry University,

Chitwan, Nepal

Email: gandhivkafle@gmail.com developed countries are obtained from wild plant species (8). Dissatisfaction with conventional treatment, past good experiences, positive aspects associated with herbal medicine, as well as family traditions were the most commonly mentioned reasons why herbal medicines were preferred as treatment (9). It is assumed that there will be exponential rise in acceptance and utilization of herbal products globally. People are using herbal and traditional medicines to treat a number of illnesses in Asian countries (10) as these medicines and their constituents have advantage to keep the body fit and health such diseases for long run (11). Increased attention to medicinal plant consumption and its dynamics may contribute to the development of collaboration across the natural resources and health sectors, resulting in more comprehensive and efficient health policies (1).

In all systems of traditional medicine, the fundamentals are to use the medicinal plants in the treatment and prevention of disease, as well as in the maintenance of health (12). People are using traditional medicine prepared using medicinal plant since a long time for prevention and cure of a number of health disorders, particularly for chronic diseases. Global interest has raised on these medicines and it can further rise in future (13). Ayurvedic medicine (also called Ayurveda) is a form of traditional medicine $(13,14,15)$. 
Ayurveda is a Sanskrit word that means the knowledge of life or the science of perfect health. It is a system of healing which originated in India 5000 years ago, based on natural, spiritual and herbal remedies. It is often called as the "Mother of all healing" which is believed to bring harmony and balance in mind, body, spiritual wellbeing and social welfare of human (16). It is a holistic and multidimensional medical system with inbuilt capacity to diagnose and treat various illnesses including chronic diseases (17). Ayurveda employs a personalized, multi-factorial approach to health care and cure, as opposed to the generalized and single target strategy of biomedicine (18). It is getting global acceptance primarily due to its age-old therapeutic practice, profound conceptual basis and survival of its medicines for thousands of year (19). Easy availability, easy biodegradability, ease to handling, low price, mankind and environment friendly nature both and minimum side effect have been speculated for the greater acceptance of Ayurvedic medicines among the patients (20).

Safety, quality and efficacy are the basic requirements for utilization of herbal medicines which can be arranged by a drug regulatory framework (21). It is necessary to know why people are using traditional medicines in order to build a knowledge-based policy on these medicines (13). Ayurveda is recognized as a national method of therapy/treatment in Nepal (22). For developing and maintaining a better healthcare system, integrated evidence based research on Ayurveda is essential (23). In this context, this research was conducted to explore the reasons for consumption of Ayurvedic medicines by patients of Nepal, with a case study on Ayurvedic medicines containing Neopicrorhiza scrophulariiflora in Nepal.

\section{Introduction to Neopicrorhiza scrophulariiflora}

Neopicrorhiza scrophulariiflora (Pennell) D. Y. Hong (Scrophulariaceae) (hereinafter referred as $N$. scrophulariiflora) is a perennial alpine herb found in the subalpine as well as alpine zone of the eastern Himalayas comprising Sikkim, Nepal, Bhutan and China. It occurs in wild in diverse habitat types: alpine grassland and gravelly areas, forests, scrublands, meadows, cliffs and screes, between 3600-4400 masl $(24,25,26)$. It prefers moist north-facing slopes with richer and partial shady soil (26). Its Nepali name is Kutki, which is assessed as being vulnerable in Nepal (27). N. scrophulariiflora is prioritized by Government of Nepal for research and economic development among 30 medicinal and aromatic plants (28).

The long, creeping and bitter rhizomes of $N$. scrophulariiflora are used medicinally. In Nepal, people are using the unprocessed rhizomes of this species as folk remedies to treat a number of health disorders as indicated in $(29,30,31,32,33,34,35,36)$.

\section{Methods}

Two surveys were conducted: a) Survey of patients consuming Ayurvedic medicines and b) Survey of patients consuming Ayurvedic medicines containing N. scrophulariiflora. a) Survey of patients consuming Ayurvedic medicines: An online survey was administered in September 2017 using SurveyMonkey tool, founded in 1999 by Ryan Finley, using a structured questionnaire to document the reasons for choosing to consume Ayurvedic medicines by citizens of Nepal.

b) Survey of patients consuming Ayurvedic medicines containing Neopicrorhiza scrophulariiflora: A survey focusing on consumers of Ayurvedic medicines containing $N$. scrophularififlora was conducted during March-July 2017. Data were collected from face to face interviews using a structured questionnaire with the purchasers of the Ayurvedic medicines containing $N$. scrophulariiflora in Bharatpur (83), Birgunj (9), Butwal (155), Gorkha bazaar (23) and Kathmandu (136). Four hundred six people who purchased those medicines for self-consumption to treat their illnesses (hereafter referred as 'patients') were only considered in this paper. The patients were asked 'why do you choose to consume these Ayurvedic medicines for treatment?'. The question was open ended and the free responses of patients were noted as it is. The patients were encouraged to tell the reason/s for choosing to consume those Ayurvedic medicines freely in their own words and as much as they could and wished. The words 'patient', 'consumer' and 'respondent' are used interchangeably in this paper.

The responses were entered into Microsoft excel and coding was done reading line by line. Conceptually similar responses were coded using uniform words and grouped accordingly.

\section{Results}

1. Patients consuming Ayurvedic medicines

1.1 Characteristics of respondents (Ayurvedic medicine consumers)

Out of 58 consumers, $51(87.10 \%)$ were male and 7 $(12.90 \%)$ were female. Out of 58 respondents, 25 $(49.18 \%)$ had graduate level of education, $20(32.79 \%)$ had post graduate level, $10(16.39 \%)$ had intermediate level and $3(1.64 \%)$ had school leaving certificate level of education (Table 1$)$.

Table 1: Characteristics of respondents (Ayurvedic medicine consumers) $(n=58)$.

\begin{tabular}{|l|l|l|}
\hline Variable & Frequency & $\%$ \\
\hline Sex of the respondent & 51 & 87.1 \\
\hline Male & 7 & 12.9 \\
\hline Female & 3 & 1.6 \\
\hline Education of respondent & \\
\hline $\begin{array}{l}\text { School leaving certificate and } \\
\text { equivalent }\end{array}$ & 3 & 16.3 \\
\hline Intermediate and equivalent & 10 & 49.1 \\
\hline Graduate and equivalent & 25 & 32.7 \\
\hline $\begin{array}{l}\text { Postgraduate, equivalent and } \\
\text { above }\end{array}$ & 20 & \\
\hline
\end{tabular}




\begin{tabular}{|l|l|l|}
\hline \multicolumn{3}{|c|}{ Household income of consumer (cash) USD/year } \\
\hline $0-934.5$ & 4 & 6.8 \\
\hline $934.6-1869.1$ & 7 & 12.0 \\
\hline $1869.2-2803.7$ & 9 & 15.5 \\
\hline $2803.8-3738.3$ & 7 & 12.0 \\
\hline $3738.4-4672.8$ & 8 & 13.7 \\
\hline Above 4672.8 & 23 & 39.6 \\
\hline
\end{tabular}

Flat exchange rate: USD $1=$ NRs 107 (7 May, 2018); USD = United States Dollar, NRs $=$ Nepalese Rupees

\subsection{Reasons for choosing to consume Ayurvedic medicines}

Fifty eight valid individual responses of consumers of Ayurvedic medicines were obtained. A total of five major reasons were identified that patients indicated for choosing to consume Ayurvedic medicines for treatment: Fewer or no side effects, belief regarding healing of disease, preference to natural way of healing, ease of access (availability and cost), and advertisement and recommendation from others (Table 2).

Table 2: Reasons for choosing to consume Ayurvedic Medicines $(\mathbf{n}=\mathbf{5 8})$.

\begin{tabular}{|l|c|c|c|}
\hline Reasons & Frequency & $\mathbf{\%}$ & Probability \\
\hline $\begin{array}{l}\text { Fewer or no } \\
\text { side effects }\end{array}$ & 30 & 51.7 & 15.5 \\
\hline $\begin{array}{l}\text { Belief } \\
\text { regarding } \\
\text { healing of } \\
\text { disease }\end{array}$ & 9 & 15.6 & 1.4 \\
\hline $\begin{array}{l}\text { Preference to } \\
\text { natural way of } \\
\text { healing }\end{array}$ & 6 & 10.3 & 0.6 \\
\hline $\begin{array}{l}\text { Ease of access } \\
\text { availability } \\
\text { and cost) }\end{array}$ & 7 & 12.1 & 0.8 \\
\hline $\begin{array}{l}\text { Advertisement } \\
\text { and } \\
\text { recommendatio } \\
\text { n from others }\end{array}$ & 6 & 10.3 & 0.6 \\
\hline
\end{tabular}

\section{Fewer or no side effects}

Out of 58 respondents, 30 respondents indicated that they chose to consume Ayurvedic medicines believing that these medicines have fewer or no side effects to body. They reported of their thoughts of not any chemical modification in Ayurvedic medicines, in that they are natural products. Some of the remarks made by respondents are as follows:

\section{Respondent\#1}

Because no any chemical modification is done in the Ayurvedic medicines. I believe that they are produced naturally that may have minimum side effects in human body.

Respondent\#2

Ayurvedic medicine has little side effects.
Respondent\#4

I believe that Ayurvedic medicine will not have any side effect.

Respondent\#8

The side effects are always less than the allopathic medicine.

\section{Respondent\#23}

Ayurvedic medicine has low side effects in comparison to allopathic medicine.

Respondent\#34

Ayurvedic medicines have minimum side effects. They are natural products with less synthetic added.

\section{Respondent\#40}

Ayurvedic medicine is pure and natural. It has no or so little side effects.

\section{Belief regarding healing of disease}

Out of 58 respondents, nine respondents had belief of treatment of disease from Ayurvedic medicines. One respondent preferred to consume Ayurvedic medicine if allopathic medicine does not work and another respondent believed that Ayurveda takes into account individuality when prescribing holistic treatments. Past healing was successful from Ayurvedic medicines. Some of the remarks made by respondents are as follows:

\section{Respondent\#14}

Ayurvedic medicine has fewer side effects. Some of these medicines act as rejuvenation and preventive medicines. Some diseases are only cured using these medicines with very less side effects.

\section{Respondent\#46}

I used Ayurvedic medicine because it healed my disease in the past also.

\section{Preference to natural way of healing}

Out of 58 respondents, six respondents reported that they chose to consume Ayurvedic medicines because they preferred natural way of healing. Ayurvedic medicines are free from chemical ingredients and cure diseases in natural way. Some of the remarks made by respondents are as follows:

Respondent\#3

It's natural way of treatment with Ayurvedic medicine.

Respondent\#10

I prefer Naturopathy for treatment.

\section{Ease of access (availability and cost)}

Out of 58 respondents, seven respondents believed that Ayurvedic medicines are cheaper and easily available in local market. Some of the remarks made by respondents are as follows: 
Respondent\#21

Ayurvedic medicine is cheap.

Respondent\#15

Ayurvedic medicines are easily available locally and in wild.

\section{Advertisement and recommendation from others}

Out of 58 respondents, six respondents considered advice and recommendation from others such as family, doctor, seniors, advertisement and culture, coupled with own knowledge in some cases. Some of the remarks made by respondents are as follows:

\section{Respondent\#30}

I consulted Ayurvedic doctor then consumed Ayurvedic medicine.

\section{Respondent\#32}

Ayurvedic medicine use was linked with family recommendation and own knowledge.

\section{Respondent\#33}

I consumed Ayurvedic medicines after seeing the advertisement. I prefer to promote Asian herbs. I have spiritual belief on Ayurvedic medicines.

\section{Survey of patients consuming Ayurvedic medicines containing Neopicrorhiza scrophulariiflora (Pennell) D. Y. Hong.}

A survey on consumption of $N$. scrophulariiflora was conducted to explore why the patients chose to consume the Ayurvedic medicines containing this species. N. scrophulariiflora is found in the eastern Himalayas comprising Sikkim, Nepal, Bhutan and China. It is a perennial alpine herb found in the subalpine as well as alpine zone. The findings are presented below:

\subsection{Characteristics of patients}

Out of 406 patients, 232 (57.1\%) were male and $174(42.9 \%)$ were female. All respondents purchased the Ayurvedic medicines containing Neopicrorhiza for their own consumption. By location, those respondents were from Bharatpur (83), Birgunj (9), Butwal (155), Gorkha bazaar (23) and Kathmandu (136). The characteristics of patients are presented in Table 3.

Table 3: Characteristics of respondents $(n=406)$.

\begin{tabular}{|l|l|l|}
\hline Variable & Frequency & $\%$ \\
\hline Age of the respondent (year) \\
\hline $10-19$ & 28 & 6.9 \\
\hline $20-29$ & 101 & 24.8 \\
\hline $30-39$ & 113 & 27.8 \\
\hline $40-49$ & 86 & 21.1 \\
\hline $50-59$ & 49 & 12.0 \\
\hline $60-69$ & 21 & 5.1 \\
\hline $70-79$ & 5 & 1.2 \\
\hline $80-89$ & 3 & 0.7 \\
\hline
\end{tabular}

\begin{tabular}{|c|c|c|}
\hline Variable & Frequency & $\%$ \\
\hline \multicolumn{3}{|c|}{ Education of respondent } \\
\hline Illiterate & 31 & 7.6 \\
\hline Primary education & 47 & 11.5 \\
\hline $\begin{array}{l}\text { Lower secondary } \\
\text { education }\end{array}$ & 26 & 6.4 \\
\hline Secondary education & 37 & 9.1 \\
\hline SLC and equivalent & 67 & 16.5 \\
\hline $\begin{array}{l}\text { Intermediate and } \\
\text { equivalent }\end{array}$ & 109 & 26.8 \\
\hline $\begin{array}{l}\text { Graduate and } \\
\text { equivalent }\end{array}$ & 67 & 16.5 \\
\hline $\begin{array}{l}\text { Postgraduate, } \\
\text { equivalent and above }\end{array}$ & 22 & 5.4 \\
\hline \multicolumn{3}{|c|}{$\begin{array}{l}\text { Household income of consumer (cash) USD/ } \\
\text { year }\end{array}$} \\
\hline $0-934.5$ & 73 & 17.9 \\
\hline $934.6-1869.1$ & 130 & 32.0 \\
\hline $1869.2-2803.7$ & 64 & 15.7 \\
\hline $2803.8-3738.3$ & 42 & 10.3 \\
\hline $3738.4-4672.8$ & 42 & 10.3 \\
\hline Above 4672.8 & 55 & 13.5 \\
\hline \multicolumn{3}{|c|}{ Occupation of the consumer } \\
\hline Business & 113 & 27.8 \\
\hline Farmer & 56 & 13.7 \\
\hline Housewife & 61 & 15.0 \\
\hline Job holder (on salary) & 100 & 24.6 \\
\hline Student & 71 & 17.4 \\
\hline Unemployed & 5 & 1.2 \\
\hline
\end{tabular}

Flat exchange rate: USD $1=$ NRs 107 (7 May, 2018); USD = United States Dollar, NRs $=$ Nepalese Rupees.

\subsection{Reasons for choosing to consume Ayurvedic medicines containing Neopicrorhiza scrophulariiflora}

A total of 511 responses were obtained from 406 patients regarding the reasons for consuming Ayurvedic medicines that contain $N$. scrophulariiflora in Nepal. It has been found that the patients considered a number of factors while deciding to consume Ayurvedic medicines containing $N$. scrophulariiflora. The top seven reasons for choosing to consume these medicines were: no side effects on body, cure of illness for long run, unsuccessful healing from allopathic and other types of medicines in the past, lesser side effects than allopathic medicines, belief of beneficial to health, considering advice from family members, neighbors and friends and belief of cure of illnesses (Table 4). All the factors that the patients considered while making decision for consumption of Ayurvedic medicines containing $N$. scrophulariiflora are presented in Table 4. 
Gandhiv Kafle et.al., Why do patients choose to consume Ayurvedic Medicines in Nepal? An exploratory study

Table 4: Factors considered by patients on decision making for consumption of Ayurvedic medicines containing $N$. scrophulariiflora

\begin{tabular}{|c|c|c|c|c|}
\hline S.N. & $\begin{array}{l}\text { Factors considered by patients on decision making for } \\
\text { consumption }\end{array}$ & Frequency & Percentage & Probability \\
\hline 1 & No side effects on body & 155 & 30.3 & 47.01 \\
\hline 2 & Belief of cure of illnesses for long run & 79 & 15.4 & 12.2 \\
\hline 3 & $\begin{array}{l}\text { Unsuccessful healing from allopathic and other types of } \\
\text { medicines in past }\end{array}$ & 49 & 9.5 & 4.6 \\
\hline 4 & Lesser side effects than allopathic medicines & 36 & 7.0 & 2.5 \\
\hline 5 & Belief of beneficial to health & 24 & 4.6 & 1.1 \\
\hline 6 & $\begin{array}{l}\text { Considering advice from family members, neighbors and } \\
\text { friends }\end{array}$ & 23 & 4.5 & 1.0 \\
\hline 7 & Belief of cure of illnesses & 20 & 3.9 & 0.7 \\
\hline 8 & $\begin{array}{l}\text { No need for operation of body parts for healing with } \\
\text { Ayurvedic medicines }\end{array}$ & 19 & 3.7 & 0.7 \\
\hline 9 & Belief of quick recovery & 13 & 2.5 & 0.3 \\
\hline 10 & Effectiveness in healing chronic illnesses & 12 & 2.3 & 0.2 \\
\hline 11 & Domestic natural product & 12 & 2.3 & 0.2 \\
\hline 12 & Reliable for consumption & 9 & 1.7 & 0.1 \\
\hline 13 & Better than allopathic medicines for healing & 9 & 1.7 & 0.1 \\
\hline 14 & Easy to consume & 7 & 1.3 & 0.09 \\
\hline 15 & Not habit forming (no addiction) & 6 & 1.1 & 0.07 \\
\hline 16 & Belief of its better quality than other medicine types & 6 & 1.1 & 0.07 \\
\hline 17 & Healing was successful from Ayurvedic medicines in past & 6 & 1.1 & 0.07 \\
\hline 18 & $\begin{array}{l}\text { After seeing consumption by family members, neighbors } \\
\text { and friends }\end{array}$ & 6 & 1.1 & 0.07 \\
\hline 19 & $\begin{array}{l}\text { After seeing successful healing of family members and } \\
\text { friends by Ayurvedic medicines }\end{array}$ & 5 & 0.9 & 0.04 \\
\hline 20 & Cheaper than allopathic medicines & 4 & 0.7 & 0.03 \\
\hline 21 & Safe for long term consumption & 2 & 0.3 & 0.007 \\
\hline 22 & Relevant to all age group patients & 2 & 0.3 & 0.007 \\
\hline 23 & After hearing positive from others & 2 & 0.3 & 0.007 \\
\hline 24 & Belief of helping to look young & 1 & 0.1 & 0.001 \\
\hline 25 & Belief of increasing lifespan & 1 & 0.1 & 0.001 \\
\hline 26 & Belief of preventing occurrence of illnesses in body & 1 & 0.1 & 0.001 \\
\hline 27 & Can be consumed in whatever condition the patient is & 1 & 0.1 & 0.001 \\
\hline \multirow[t]{2}{*}{28} & Easily available to purchase & 1 & 0.1 & 0.001 \\
\hline & TOTAL & 511 & & \\
\hline
\end{tabular}

\section{Discussion}

We found that the patients chose to consume Ayurvedic medicines because they believed that Ayurvedic medicines have fewer or no side effects to body; can heal the disease; ensure natural way of healing; are easily available and cheaper; and are recommended by others such as family, doctor, seniors, advertisement and culture. The most important reason for choice of consumption of Ayurvedic medicines was belief of patients regarding fewer or no side effects to their bodies associated with their consumption. In the case of factors considered by patients on decision making for consumption of Ayurvedic medicines containing N. scrophulariiflora, belief of not having any side effects, cure of illness for long run and unsuccessful healing from allopathic and other types of medicine in the past were the top three factors. Other causal factors were lesser side effects than allopathic medicines, belief of beneficial to health, considering advice from family members, neighbors and friends and belief of cure of illnesses. In case of N. scrophulariiflora also, belief of the patients on not having any side effects to their bodies was the major reason for their choice to consume its medicines. Some ideas have been developed from the findings: The patients considered multiple factors to evaluate whether to choose to consume Ayurvedic medicines or not. For example, five major reasons were identified for their choice of Ayurvedic medicines and multitude factors while choosing to consume Ayurvedic medicines containing N. scrophulariiflora. The patients were aware about the side effects of medicines other than Ayurvedic medicines, and about the none or lesser side effects of the Ayurvedic medicines on 
their bodies. The patients were also motivated to heal their illnesses for long run. They were also dependent on anecdotal information for example, after seeing successful healing of family members and friends by Ayurvedic medicines; after hearing positive from others; and after seeing consumption by family members, neighbors and friends (Table 4). In this respect, choice of freedom of the patients for healthcare methods (i.e. Ayurvedic medicines or allopathic or other types) based on a number of factors exists in Nepal (Table 4). Similar reasons were identified by Aziato and Antwi (37) and Parle and Bansal (38) such as perceived ineffectiveness of western medicine, adopting a deductive approach based on anecdotal information, that is, "it worked for my friend or relative".

Our findings are consistent with Welz et al. (9) who found that treating illness was the most frequently discussed aim for using herbal medicine over all age groups in Germany, Aydin et al. (39) who found that the reasons for the use of herbal medicine were mostly for prevention and for treatment, and Issa and Basheti (40) who found that a high proportion of customers reported to have high beliefs in herbal medicine efficacy and safety over conventional medicine in Jordan. Welz et al. (9) reported that treating illness was the most frequently discussed aim for using herbal medicine over all age groups in Germany. Oreagba et al. (41) found that family and friends had a marked influence on majority of the respondents who used herbal medicine preparation among urban residents in Lagos, Nigeria. About half of the respondents in this study considered that herbal medicines were safe. Jaouhari et al. (42) reported that family members were the main source of information for the decision making on use of herbal medicines by adult surgical patients in Morocco.

\section{Limitations}

Survey Monkey tool was used in online survey, so the educated persons having computer or mobile phone with internet connection might have responded the questions. It is also reflected in the educational status of the majority of respondents having higher education. In this paper, we only presented findings qualitatively identifying the common themes for the reasons for choosing to consume Ayurvedic medicines. Moreover, the sample size is small $(\mathrm{n}=58)$, hence it is considered an elicitation type of study to explore the respondent's choice reasons for consumption of Ayurvedic medicine. Similar elicitation study with small number of samples is recommended and in practice in studies of consumer behavior using Theory of Planned Behavior (43).

Despite these limitations, the findings of this study has made a number of contributions to understanding of reasons for consumption of Ayurvedic medicines in Nepal from the perspectie of nursing practice. Firstly, the findings have confirmed that Nepalese people have great faith on Ayurvedic medicines indicating no side effects and have dependency on these medicines for treating their illnesses. Secondly, the results have provided useful information to the Ayurvedic health practitioners about the beliefs of the patients about Ayurvedic medicines and their consumption, and that could be used to improve the Ayurvedic medicine system in Nepal in relation to patient safety. Thirdly, this research has identified factors perceived by the patients on Ayurvedic medicines that led them to choose Ayurvedic medicinal system for example, fewer or no side effects, effective in healing chronic illnesses, better than allopathic medicines for healing etc. These factors are important for health authorities, nursing practitioners and related stakeholders in Nepal about which they can conduct further research and validation.

\section{Conclusions}

The patients chose to consume Ayurvedic medicines in Nepal considering that Ayurvedic medicines have fewer or no side effects to body; can heal the disease; ensure natural way of healing; are easily available and cheaper; and are recommended by others such as family, doctor, seniors, advertisement and culture. The major factors that encourage decision making to consumption of Ayurvedic medicines containing Neopicrorhiza scrophulariiflora were belief of patients of not having side effects from these medicines, cure of illness for long run and unsuccessful healing from allopathic and other types of medicine in the past. Further scientific research is recommended to validate the effectiveness and safety of Ayurvedic medicines. As majority of the consumers of Ayurvedic medicines believe fewer or no side effects to body of the Ayurvedic medicines in Nepal and cure of illness for long run, the government authorities such as the Department of Ayurveda of Government of Nepal should facilitate quality control in the manufacturing of these medicines to ensure patient safety. Finally, the research has provided the policy makers and nursing practitioners working to enhance the present healthcare system by answering on why people are preferring Ayurvedic medicine system rather than the allopathic and present mainstream biomedical system for healthcare.

\section{Data Availability}

The data used to support the findings of this study are available from the corresponding author upon written request.

\section{Acknowledgements}

The study was financed by a scholarship to the first author from the Research Committee for Development Research (FFU) of the Danish Ministry of Foreign Affairs, Grant No. 13-07KU, the "Transiting to Green Growth: Natural Resources in Nepal" project. We are highly grateful to the enumerators for assisting in data collection. We express our sincere gratitude for the consumers of Ayurvedic medicines and the Neopicrorhiza-containing Ayurvedic medicines who agreed to respond in online and face to face surveys respectively. We are highly grateful to Prof. Dr. Carsten Smith-Hall and Dr. Mariéve Pouliot of University of Copenhagen, Dr. Suresh Kumar Ghimire of Tribhuvan University of Nepal, Prof. Dr. Abhoy Kumar Das of 
Federation of Community Forestry Users Nepal (FECOFUN) and Dr. Shiva Chandra Dhakal of Agriculture and Forestry University of Nepal for providing advice on different stages of study.

\section{References}

1. Smith-Hall C, Larsen HO, Pouliot M. People, plants and health: a conceptual framework for assessing changes in medicinal plant consumption. Journal of Ethnobiology and Ethnomedicine. 2012 Dec;8 (1):43.

2. Samuelsson G, Bohlin L. Drugs of natural origin: a treatise of pharmacognosy. CRC Press Inc.; 2017.

3. Chacko SM, Thambi PT, Kuttan R, Nishigaki I. Beneficial effects of green tea: a literature review. Chinese medicine. 2010 Dec;5(1):13.

4. Nalawade SM, Sagare AP, Lee CY, Kao CL, Tsay HS. Studies on tissue culture of Chinese medicinal plant resources in Taiwan and their sustainable utilization. Bot. Bull. Acad. Sin. 2003 Apr 1;44:7998.

5. Hinman JW. Round table discussion on inflammation. In R.H. Kahn, W.E.M. Lands (Eds.), Prostaglandins and Cyclic AMP. Biological Actions and Clinical Applications. Academic Press, New York; 1973.

6. Wu CH, Wang CC, Tsai MT, Huang WT, Kennedy $\mathrm{J}$. Trend and pattern of herb and supplement use in the United States: results from the 2002, 2007, and 2012 national health interview surveys. EvidenceBased Complementary and Alternative Medicine. 2014;2014.

7. Zhang AL, Story DF, Lin V, Vitetta L, Xue CC. A population survey on the use of 24 common medicinal herbs in Australia. Pharmacoepidemiology and drug safety. 2008 Oct;17(10):1006-13.

8. Hamilton AC. Medicinal plants, conservation and livelihoods. Biodiversity \& Conservation. 2004 Jul $1 ; 13(8): 1477-517$.

9. Welz, A. N., Emberger-Klein, A., \& Menrad, K. (2018). Why people use herbal medicine: insights from a focus-group study in Germany. $B M C$ complementary and alternative medicine, 18(1), 92.

10. Prasad S, Tyagi AK. Traditional medicine: the goldmine for modern drugs. Adv Tech Biol Med. 2015;3(1):1-2.

11. Luqman S, Rizvi SI, Beer AM, Khare SK, Atukeren P. Efficacy of herbal drugs in human diseases and disorders. Evidence-Based Complementary and Alternative Medicine. 2014;2014.

12. Acharya D, Shrivastava A. Indigenous herbal medicines. Aavishkar Publishers, Distributors; 2008.

13. WHO. WHO Traditional Medicine Strategy 20142023. Geneva; 2013.

14. WHO. The promotion and development of traditional medicine. Report of a WHO meeting. InThe promotion and development of traditional medicine. Report of a WHO meeting. 1978 (No. 622). Geneva, Switzerland..

15. Van Galen E. Traditional herbal medicines worldwide, from reappraisal to assessment in
Europe. Journal of ethnopharmacology. 2014 Dec 2;158:498-502.

16. Gerson S. Ayurveda: The ancient Indian healing art. Element; 1993.

17. Bhandari M, Ravipati AS, Reddy N, Koyyalamudi SR. Traditional Ayurvedic medicines: Pathway to develop anti-cancer drugs. Journal of Molecular Pharmaceutics and Organic Process Research. 2015;3(3).

18. Patwardhan B. The quest for evidence-based Ayurveda: lessons learned. Current science. 2012 May 25:1406-17.

19. Mukherjee PK, Katiyar CK, Patwardhan B. Special issue on Ayurveda. Journal of ethnopharmacology. 2017 Feb 2;197:2.

20. Meena AK, Bansal P, Kumar S. Plants-herbal wealth as a potential source of ayurvedic drugs. Asian Journal of Traditional Medicines. 2009;4 (4): $152-70$.

21. Ekor M. The growing use of herbal medicines: issues relating to adverse reactions and challenges in monitoring safety. Frontiers in pharmacology. 2014 Jan 10;4:177.

22. DOA/GON. The National Ayurveda Health Policy 2052 (1996). Department of Ayurveda, Ministry of Health, Government of Nepal. Kathmandu; 1996.

23. Mukherjee PK, Harwansh RK, Bahadur S, Banerjee S, Kar A, Chanda J, Biswas S, Ahmmed SM, Katiyar CK. Development of ayurveda-tradition to trend. Journal of ethnopharmacology. 2017 Feb 2;197:10-24.

24. Shrestha BB, Gewali MB, Jha PK. Ecology of Neopicrorhiza scrophulariiflora (Pennell) Hong. Growing under Different Land Uses in a TransHimalayan Dry Valley of Central Nepal. International Journal of Ecology and Environmental Sciences. 2007;33(4):233-41.

25. Ghimire SK, McKey D, Aumeeruddy-Thomas Y. Conservation of Himalayan medicinal plants: Harvesting patterns and ecology of two threatened species, Nardostachys grandiflora DC. and Neopicrorhiza scrophulariiflora (Pennell) Hong. Biological Conservation. 2005 Aug 1;124(4):46375.

26. Shrestha BB, Jha PK. Habitat range of two alpine medicinal plants in a trans-Himalayan dry valley, Central Nepal. Journal of Mountain Science. 2009 Mar 1;6(1):66-77.

27. Tandon V, Bhattarai NK, Karki M. Conservation assessment and management plan workshop report on selected medicinal plant species of Nepal., 18-20 January 2001, Pokhara, Nepal. Medicinal and Aromatic Plants Programme in Asia (MAPPA), IDRC and Ministry of Forests and Soil Conservation, Nepal. 2001.

28. HNCC. Prioritized medicinal plants for economic growth in Nepal. Herbs and NTFPs Co-ordination Committee, Department of Plant Resources, Ministry of Forest and Soil Conservation, Government of Nepal, Kathmandu, Nepal; 2006.

29. Pohle P. Useful plants of Manang district: A contribution to the ethnobotany of Nepal Himalaya. 
Frantz Steiner Verlag Wieabadan GMBH, Stuttgart, Germany; 1990.

30. Lama YC, Ghimire SK, Aumeeruddy-Thomas Y. Medicinal plants of Dolpo. Amchis' knowledge and conservation. WWF Nepal Program, Katmandu. 2001.

31. Manandhar NP. Plants and people of Nepal. Timber press; 2002.

32. Kunwar RM, Adhikari N. Ethnomedicine of Dolpa district, Nepal: the plants, their vernacular names and uses. Lyonia. 2005 Jul;8(1):43-9.

33. Bhattarai S, Chaudhary RP, Taylor RS. Ethnomedicinal plants used by the people of Manang district, central Nepal. Journal of Ethnobiology and Ethnomedicine. 2006 Dec;2 (1):41.

34. Pandit BH, McDougall C, Kumar C, Mallik AK. Issues in integration of medicinal plants with farm crop cultivation: learning from farmers of the eastern hills of Nepal. Medicinal Plants in Nepal: An Anthology of Contemporary Research. 2008:146 $-51$.

35. Prasai D, Shrestha KK. Ethnomedicinal knowledge of Tamang communities in Rasuwa district. Medicinal Plants in Nepal: An Anthology of Contemporary Research. 2008:146-51.

36. Uprety Y, Asselin H, Boon EK, Yadav S, Shrestha KK. Indigenous use and bio-efficacy of medicinal plants in the Rasuwa District, Central Nepal. Journal of Ethnobiology and Ethnomedicine. 2010 Dec;6 (1):3.
37. Aziato L, Antwi HO. Facilitators and barriers of herbal medicine use in Accra, Ghana: an inductive exploratory study. BMC complementary and alternative medicine. 2016 Dec;16(1):142.

38. Parle M, Bansal N. Herbal medicines: are they safe? Nat. Prod. Rad. 5 6-14; 2006.

39. Aydin S, Bozkaya AO, MAZICIOĞLU MM, Gemalmaz A, Özçakir A, Öztürk A. What influences herbal medicine use?-prevalence and related factors. Turkish Journal of Medical Sciences. 2008 Sep 26;38(5):455-63.

40. Issa RA, Basheti IA. Herbal products use among chronic patients and its impact on treatments safety and efficacy: a clinical survey in the Jordanian field. Trends Med Res. 2016;12:32-44.

41. Oreagba IA, Oshikoya KA, Amachree M. Herbal medicine use among urban residents in Lagos, Nigeria. BMC Complementary and Alternative medicine. 2011 Dec;11(1):117.

42. Jaouhari SD El, Meziane M, Touab R, Jaafari AI, Lalaoui JS and Bensghir M. Herbal Medicine: A Survey of use in Moroccan Surgical Patients. 5:2; 2018.

43. Ajzen I. The theory of planned behavior. Organizational behavior and human decision processes. 1991 Dec 1;50(2):179-211. 